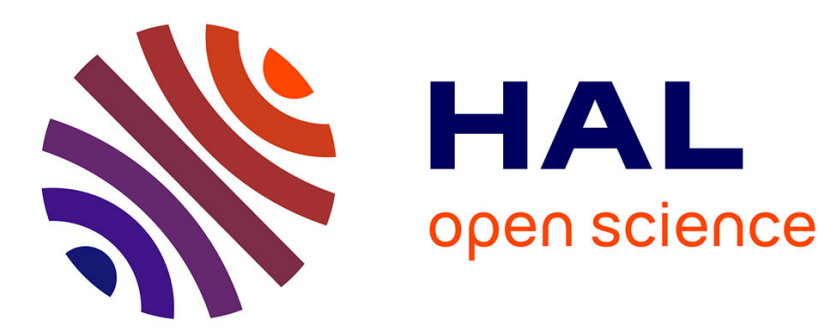

\title{
Mechanical Frequency Tuning by Sensory Hair Cells, the Receptors and Amplifiers of the Inner Ear
}

\author{
Pascal Martin, A.J. Hudspeth
}

\section{To cite this version:}

Pascal Martin, A.J. Hudspeth. Mechanical Frequency Tuning by Sensory Hair Cells, the Receptors and Amplifiers of the Inner Ear. Annual Review of Condensed Matter Physics, 2021, 12 (1), 10.1146/annurev-conmatphys-061020-053041 . hal-03036747

\section{HAL Id: hal-03036747 https://hal.science/hal-03036747}

Submitted on 16 Dec 2020

HAL is a multi-disciplinary open access archive for the deposit and dissemination of scientific research documents, whether they are published or not. The documents may come from teaching and research institutions in France or abroad, or from public or private research centers.
L'archive ouverte pluridisciplinaire HAL, est destinée au dépôt et à la diffusion de documents scientifiques de niveau recherche, publiés ou non, émanant des établissements d'enseignement et de recherche français ou étrangers, des laboratoires publics ou privés. 


\section{Mechanical frequency tuning by sensory hair cells, the receptors and amplifiers of the inner ear}

Pascal Martin ${ }^{1,2}$ and A. J. Hudspeth ${ }^{3}$

${ }^{1}$ Laboratoire Physico-Chimie Curie, Institut Curie, PSL Research University, CNRS UMR168, 75248 Paris Cedex 05, France; E-mail: pascal.martin@curie.fr

${ }^{2}$ Sorbonne Université, 75005 Paris, France.

${ }^{3}$ Howard Hughes Medical Institute and Laboratory of Sensory Neuroscience, The Rockefeller University, New York, NY 10065, USA; email: hudspaj@rockefeller.edu

Corresponding author: Dr. A. J. Hudspeth (ORCID 0000-0002-0295-1323)

Laboratory of Sensory Neuroscience

The Rockefeller University

New York, NY 10065, USA

Telephone: 1-212-327-7351

Facsimile: 1-212-327-7352

E-mail: hudspaj@rockefeller.edu

\section{Keywords}

auditory system, cochlea, hair bundle, Hopf bifurcation, transduction, traveling wave 


\begin{abstract}
We recognize sounds by analyzing their frequency content. Different frequency components evoke distinct mechanical waves that each travel within the hearing organ, or cochlea, to a frequency-specific place. These signals are detected by hair cells, the ear's sensory receptors, in response to vibrations of mechanically sensitive antennas termed hair bundles. An active process enhances the sensitivity, sharpens the frequency tuning, and broadens the dynamic range of hair cells through several mechanisms, including active hair-bundle motility. A dynamic interplay between negative stiffness mediated by ion channels' gating forces and delayed force feedback owing to myosin motors and channel reclosure by calcium ions brings the hair bundle to the vicinity of an oscillatory instability - a Hopf bifurcation. Operation near a Hopf bifurcation provides nonlinear generic features that are characteristic of hearing. Multiple gradients at molecular, cellular, and supercellular scales tune hair cells to characteristic frequencies that cover our auditory range.
\end{abstract}

\title{
Introduction
}

Imagine a strain gauge that reliably detects deflections of sub-nanometer magnitude. It responds from static deflection to periodic stimulation at frequencies approaching $200 \mathrm{kHz}$. Its dynamic range is outstanding, encompassing twelve orders of magnitude in input power. Tuned to specific input frequencies, the device can exhibit a quality factor as great as 1000. Less than $10 \mathrm{~mm}$ in diameter, it functions at high humidity-even under water-and is insensitive both to vibration and to electromagnetic interference. The system requires no cryogenic cooling; in fact, it generally operates near $310 \mathrm{~K}$.

This device is not a state-of-the art marvel of microfabrication, but rather the cochlea, or mammalian hearing organ (Figure 1a). Although no single cochlea meets all of the specifications noted above, all cochleae-including our own-are similar in development, structure, and operation. In fact, the essential features of our ears greatly 
antedate the mammalian line of evolution, so the ears of fishes, amphibians, and reptiles (including birds) share many features with those of mammals (1).

This article reviews the operation of the cochlea and its mechanoreceptorssensory hair cells-with particular emphasis on frequency tuning, which is essential for our capacity to distinguish sound sources and interpret spoken words on the basis of their acoustic spectra. Naturally occurring sounds vary widely in waveform and duration. Some sounds, such as a clap of thunder or the crash of a falling object, are transient impulses. However, most of the acoustic signals in which we are especially interested-especially those of verbal communication-are periodic in nature and last for tens to thousands of cycles. These characteristics imply that sounds can usefully be detected by a resonant system that accumulates energy across many cycles and thereby registers even very weak stimuli. We shall, in fact, analyze the ear's operation in these terms in the principal parts of this article.

While vibrating in a fluid whose viscosity would seem to preclude resonance, the cochlea nonetheless conducts a real-time frequency analysis of its inputs and represents each frequency component with high resolution. Frequency tuning stems both from the physical characteristics of the ear's components and from the emergent properties of the ear's "active process", which reflect the fact that hair cells operate far from thermodynamic equilibrium to mechanically amplify their inputs.

\section{Analyzing the features of sound}

The frequencies present in a sound are resolved in the auditory periphery by mechanisms antecedent to neural coding (2). This step occurs in two ways that are not mutually exclusive. In some auditory systems, different frequency components are separated along the receptor organ's length on the basis of the physical properties of the conductive medium. The most refined version of this approach is that of the mammalian cochlea, in which mechanical traveling waves peak at frequency-dependent positions (3). The 
mechanically sensitive hair cells at each position are then excited by only a specific band of frequencies and in turn respond best to those frequencies. The most effective frequency is termed the best or characteristic frequency. Although extrinsic filtering of the input delivered to the hair cells helps establish a frequency map along the cochlea, we shall see that the hair cells themselves sharpen the map by providing active mechanical feedback to the cochlear traveling waves. Hair-cell tuning is thus the result of both extrinsic and intrinsic mechanisms.

In simpler hearing organs, acoustic energy is distributed more-or-less equally to all the hair cells, but those cells nonetheless differ in their individual sensitivities to sounds of different frequency. Some hair cells are broadly tuned by a tuning fork-like mechanism in their mechanically sensitive organelles $(4,5)$. A hair cell can also display electrical resonance of its membrane; here the number, conductance, and kinetic properties of $\mathrm{Ca}^{2+}$ and $\mathrm{K}^{+}$channels determine the frequency at which a given cell's membrane potential resonates (6-10). This electrical tuning mechanism appears to be ubiquitous in nonmammalian vertebrates but is limited to low frequencies, up to about $1 \mathrm{kHz}$.

For each of these tuning mechanisms, hair cells are systematically arrayed along a single axis as a function of frequency. This phenomenon is termed "tonotopy" or "pitch by place." Although the relation between position and characteristic frequency is approximately linear in hearing organs with relatively few hair cells, the common pattern in more elaborate organs is a logarithmic mapping: each tenfold increment in frequency is represented by a roughly equal distance along the organ and a comparable number of hair cells. An interesting exception occurs in the cochleae of bats, which greatly overrepresent the narrow range of frequencies at which the animals vocalize and to which their sonar is most sensitive $(11,12)$. In contrast, most ears operate over a broad frequency range (13); in humans, hearing spans three orders of magnitude, from $20 \mathrm{~Hz}$ to $20 \mathrm{kHz}$. Because each hearing organ is endowed with only a few thousand hair cells, it can devote only a limited number of sensory cells to the detection of a given sound 
frequency. As discussed below, the relatively small number of hair cells may limit the signal-to-noise ratio of sound detection $(14,15)$.

\section{Mechanical and hydrodynamic features of the cochlea}

Although the anatomy and operation of the cochlea are quite complex, extensive review articles document the details $(16,17)$. The pressure changes associated with sounds are captured by the external ear and funneled into the ear canal. These pressure changes set the thin eardrum into oscillatory motion, which is propagated through the three tiny bones of the middle ear. The last of the bones, the stapes, undergoes a piston-like movement at the oval window, one of the two elastic diaphragms opening into the boneencased cochlea, and thus engenders oscillatory pressure changes there (Figure 1a). Owing to both the areal difference between the large eardrum and the tiny oval window and the system of levers represented by the bones, the apparatus of the middle ear largely matches the acoustic impedance of the air to the input impedance of the liquidfilled cochlea. This feature minimizes reflections and ensures that most of the incoming energy is transduced into electrical signals. However, optimal impedance matching occurs only at a specific frequency, about $2 \mathrm{kHz}$ in humans; the middle ear thus acts as a band-pass filter (18).

Movement of the stapes produces a pressure difference transverse to the basilar membrane, an elastic band that spirals within the cochlea and supports the receptive hair cells. As a consequence, the basilar membrane undergoes an oscillatory motion at the frequency or frequencies of stimulation. In the short cochleae of some reptiles, the entire basilar membrane moves as a unit and every hair cell receives a comparable stimulus. A key feature of the mammalian cochlea is that the basilar membrane displays gradients in stiffness and mass along its length $(3,19)$. Such a basilar membrane undergoes a more complex motion: a traveling wave originates at the base, gradually increases in amplitude as it propagates toward the apex, peaks sharply at a specific position, and then dissipates 
(20-24). Most importantly, the position of the peak is frequency-dependent: high frequencies excite the cochlear base most strongly, whereas low frequencies stimulate the apex. Intermediate frequencies are represented in monotonic order between the two extremes. The cochlea therefore acts as a real-time frequency analyzer that distributes the energy from any acoustic stimulus to specific hair cells on the basis of the signal's frequency content.

\section{Structure and function of sensory hair cells}

Oscillatory stimuli within a cochlea excite mechanically sensitive hair cells, which number about 16,000 in each human cochlea (25). The unique and essential component of a hair cell-and the source of its peculiar name-is its mechanosensitive organelle, the hair bundle (26). This structure has nothing to do with actual hair, but corresponds to a tuft of microscopic, cylindrical processes emanating from the cell's flattened top surface (Figure 1b). Each of these processes is termed a stereocilium, a name meaning "stiff hair." The lengths of stereocilia and the heights of the corresponding hair bundles vary widely, from less than $1 \mu \mathrm{m}$ to more than $50 \mu \mathrm{m}$. This variation correlates with the frequency at which the hair cell responds best: the shortest bundles operate at frequencies exceeding $100 \mathrm{kHz}$ and the longest at those below $100 \mathrm{~Hz}$. The tonotopic map in auditory organs is associated with systematic variations of hair-bundle morphology, with an inverse relation between the height and the number of stereocilia (27-29). Hair cells with higher characteristic frequencies are endowed with stiffer hair bundles $(30,31)$.

The stereocilia in every hair bundle stand in rows of increasing height (Figure 1c), and deflecting the bundle toward its tall edge-defined as the positive direction-excites the hair cell $(32,33)$. A movement in the opposite direction is inhibitory, whereas an orthogonal deflection has little or no effect. The conversion of hair-bundle deflections into electrical signals within the hair cells is conceptually simple $(16,34)$. Along the axis of 
sensitivity, each short stereocilium is attached to the side of tallest adjacent stereocilium by a $150 \mathrm{~nm}$-long protein strand termed the tip link (Figure 1d)(35). As a result of this oblique connection, the shearing motion that occurs between the two stereocilia when they move in the positive direction increases the tension in the tip link. That tension is communicated to a few mechanically sensitive channels at the link's lower insertion, which open to allow $\mathrm{K}^{+}$and $\mathrm{Ca}^{2+}$ ions to flow into the hair cell and thus to depolarize it $(36,37)$. The cell then increases its release of the synaptic transmitter glutamate, which excites the nerve fibers in contact with the hair cell (38-40).

The mechanical properties of tip links vary along the cochlea's tonotopic axis. The links are stiffer and bear more tension at the cochlear base than at the apex, and there appears to be a smooth gradient between (31). Although differences in the proteins themselves might account for this gradient, each constituent is represented by only one known gene and alternative mRNA splicing or post-translational modifications seem unlikely to be able to produce the range of observed properties. An interesting possibility is that tip links of a uniform molecular composition exhibit distinct properties as a result of strain hardening (41). Using an optical trap to extend individual molecules of protocadherin 15 , one of the two proteins constituting the tip link (42), evokes the behavior expected for entropic stiffness: as a molecule's extension increases, its tension grows superlinearly (43). Each tip link's tension is set by a molecular motor at its upper insertion. In at least some hair bundles, numerous myosin 1c molecules constitute this motor (4447); myosin 7 a molecules might also contribute $(48,49)$. The number of myosin molecules associated with each tip link or the force that each molecule can produce might rise with increasing characteristic frequency, resulting in increased tension and therefore greater stiffness. As noted below, this arrangement likely contributes to the tuning of hair bundles to specific frequencies.

The unitary conductance of the transduction channels, which is mediated in part by the pore-forming property of transmembrane channel-like proteins 1 and 2 (TMC1 and TMC2)(50-52), increases from the apex to the base of the cochlea (53-55). Each tip link 
is associated with an increasing number of TMC1 molecules along the tonotopic axis and a channel at a given cochlear location is endowed with multiple conductance states (55). The tonotopic gradient in channel conductance might actually result from a variable number of identical channels gating cooperatively within a transduction element. In any case, the magnitude of the transduction current associated with one tip link increases with the characteristic frequency of the hair cell. Because the magnitude of the transduction current acts as a control parameter of active motility by the hair cell (56-59), this feature is probably essential to modulate the frequency at which the active process boosts the input to a given hair cell.

\section{Gating of mechanoelectrical-transduction channels}

Every hair bundle acts as a mechanosensitive antenna. Deflection of a hair bundle elicits an electrical response that may be monitored by using a microelectrode to record the change in transmembrane potential of the hair cell. This response is graded with the amplitude of stimulation, but saturates at a magnitude of a few tens of millivolts (32). A more revealing technique uses a voltage-clamp circuit, which implements negative feedback to determine the ionic current that flows into a stimulated cell at a fixed potential. Normalizing the result to the maximal value provides a measure of the channel open probability $P_{0}$, which is related to deflection $X$ of the hair bundle from its resting position by a Boltzmann equation (60):

$$
P_{\mathrm{o}}=1 /\left[1+e^{-\left(X-X_{0}\right) / \delta}\right] .
$$

The parameter $X_{0}$ is the deflection at which half the channels are open. Because its value dictates the operating point $P_{\mathrm{o}}(X=0)$ of the transducer when there is no stimulus, this parameter will hereafter be called the set-point deflection. The characteristic lengthscale $\delta$ sets the width and maximal slope of the sigmoidal relation (61), and thus the operating range and mechanosensitivity of the hair bundle, respectively. 
The relation given by Equation 1 is expected from equilibrium thermodynamics if each transduction channel is endowed with only two states, opens or closes independently of the others, and is connected to an elastic element-the gating springof stiffness $\kappa$. One end of the spring is hypothesized to be attached to the channel's gate, whereas the other end moves in proportion to the hair bundle's deflection. The gating spring might correspond to the tip link or to some more compliant structure in series with it. The gating spring's stiffness can be estimated by measuring the reduction $K_{\mathrm{GS}}$ in hairbundle stiffness upon tip-link disruption $(31,62): \kappa=K_{\mathrm{GS}} / N$, in which $N$ is the number of tip links, of which there are a handful to a few hundred in various hair bundles. Channel opening reduces both the extension of and the tension in the gating spring, by the gatingswing distance $D$ and the gating force $Z=\kappa D=K_{\mathrm{GS}} D / N$, respectively. Channel closure conversely increases the gating-spring extension by $D$ and the tension by $Z$. At thermal equilibrium, the energy difference $\Delta E(X)=-Z\left(X-X_{0}\right)$ between the open and closed states of the channel sets the channel's open probability $P_{\mathrm{o}}$ at position $X$. The open probability obeys Equation 1, from which one can identify $\delta=k_{\mathrm{B}} T / Z$, in which $k_{\mathrm{B}}$ is the Boltzmann constant and $T$ is temperature. Therefore, the greater the gating force $Z$, the larger is the transduction current in response to a given deflection of the hair bundle: the parameter $Z$ controls the mechanosensitivity of the channel. Note that channel opening is stochastic, rather than deterministic: each channel flickers back-and-forth between its two states hundreds to millions of times a second.

The set-point deflection $X_{0}$ reflects the effects of two countervailing forces at the transduction channel. In the absence of any tension in the gating spring, the channel would remain shut at nearly all times: the energy difference $\Delta \mathrm{E}^{\varnothing} \approx 10 k_{\mathrm{B}} T$ between the open and closed states of the channel is large enough that thermal agitation would rarely provide the energy needed to effect opening (63). With the hair bundle at rest, however, each gating spring normally bears enough tension to open a significant fraction of the channels, resulting in an operating point at rest $P_{0}^{\mathrm{R}}=P_{\mathrm{o}}(X=0)$ that lies within the steep region of the sigmoidal relation $P_{\mathrm{o}}(X)$. This condition is necessary to ensure sensitivity to 
small hair-bundle deflections. The tension results from an active pulling force $F_{\text {mot }}^{\mathrm{R}}$ exerted by myosin molecular motors on the tip links (64). The motor force is balanced by the tension in the gating springs, which extend by a distance $X_{R}$. It follows that

$$
X_{0}=\frac{\Delta E^{\emptyset}}{Z}-X_{R} .
$$

The resting bundle is accordingly displaced in the negative direction by a distance $X_{\mathrm{SP}}=$

$F_{\text {mot }}^{\mathrm{R}} / K_{S P}$ from the position at which it would reside with no tension in the spring. Here $K_{S P}$ represents the stiffness associated with the stereociliary pivots at which the stereociliary insertions flex. Each of these pivots consists of a few dozen actin filaments $(65,66)$ that are reinforced by additional proteins (46).

\section{Open probability and adaptation of cochlear hair cells}

The mammalian cochlea is endowed with two types of hair cells that serve different functions and are associated with distinct patterns of open probability $P_{0}^{\mathrm{R}}$ at the resting position $(67,68)$. Inner hair cells, which transduce acoustic stimuli into electrical activity of auditory nerve fibers, characteristically display open probabilities near $0.2(69,70)$. In contrast, mammalian outer hair cells, which send little information to the brain but serve instead as mechanical amplifiers of input signals to the inner hair cells, operate near an open probability of $0.5(71-73)$. An open probability $P_{0}^{R}=0.2$ makes sense in light of the strategy that the inner cells use to represent high-frequency stimuli. This operating point ensures that the cells rectify sinusoidal inputs to generate a steady-state potential change at frequencies that are low-pass filtered by the cell membrane, typically beyond $3 \mathrm{kHz}$. Although the phase of the input is lost, auditory nerve fibers project to the auditory cortex according to a tonotopic map that informs the brain about the frequency of the stimulus.

The open probability $P_{0}^{R}=0.5$ is the worst insofar as electrical integration is concerned, for the Boltzmann relation between the input and the output (Equation 1) is antisymmetric about that point and a sinusoidal input yields no steady-state electrical response. An open probability of one-half is ideal, however, for a response proportional 
to the transduction current: the relation between displacement and open probability-and thus current-is steepest there. This condition is optimal for amplification of basilarmembrane vibrations by electromotility of outer hair cells, a process whereby the cell body contracts or elongates in response to depolarization or hyperpolarization, respectively (74). As discussed below, the mechanical properties of hair bundles relevant to mechanical amplification are also optimal at an open probability of one-half (75). Thus, incompatible physical requirements for sensing and amplifying high-frequency sounds, exemplified here by the open probability of the transduction channels, may explain why the mammalian cochlea has established a division of labor between the inner, sensing and outer, amplifying hair cells.

Owing to its high mechanical sensitivity, a hair bundle's operating range is narrow: the channels' open probability varies between $5 \%$ and $95 \%$ over a range of deflections $6 \delta \approx 100 \mathrm{~nm}$, less than the diameter of an individual stereocilium. Even a modest force could deflect the bundle enough to saturate its response. To prevent this, natural selection developed an adaptation process that maintains high responsiveness (76-78). Adaptation shifts the relation $P_{\mathrm{o}}(X)$ along the displacement axis to continuously reset the operating point at steady state to the resting value $P_{0}^{\mathrm{R}}$, corresponding to a change in the set-point deflection $X_{0}$. The two contributions to $X_{0}$ (Equation 2) have led to two broadand not mutually exclusive-classes of adaptation models. In the first class, "motorbased-models," adaptation occurs by an adjustment of the position at which the upper end of each tip link is anchored $(78,79)$. This repositioning changes the extension of the gating spring from the resting value $X_{R}$. More specifically, the tip link's insertion is dragged downward by tension in the link but pulled upward by molecular motors, whose activity is regulated by the intracellular concentration of $\mathrm{Ca}^{2+}(80)$. When the two forces are unbalanced, the motors move until force balance is restored and the motors stall. As a consequence of motor movements, adaptation translates the set-point deflection along the axis of displacement by a distance $X_{\mathrm{A}}$ :

$$
X_{0}=\frac{\Delta E^{\emptyset}}{Z}-X_{R}+X_{A} .
$$


In the second class of models, "Ca ${ }^{2+}$-reclosure models", the set-point deflection $X_{0}$ changes owing to alterations in the intrinsic energy difference $\Delta E^{\emptyset}$. Within this framework, adaptation occurs when $\mathrm{Ca}^{2+}$ binds to the channel, or to a closely associated protein, and stabilizes the channel's closed state $(81,82)$. A positive deflection of the hair bundle increases the $\mathrm{Ca}^{2+}$ influx into the hair bundle, resulting in an increase of $\Delta E^{\varnothing}$ and thus $X_{0}$, and evokes channel closure. Conversely, adaptation to a negative bundle deflection occurs when a decreased influx of $\mathrm{Ca}^{2+}$ destabilizes the closed state of the channel. Although adaptation clearly relies on $\mathrm{Ca}^{2+}$ feedback for most hair cells, the dependence of adaptation on $\mathrm{Ca}^{2+}$ in mammalian cochlear hair cells has been debated $(83,84)$. The lipid environment of the transduction channels might instead regulate or even mediate adaptation $(85,86)$, but the underlying mechanism remains elusive. As discussed below, all the manifestations of active hair-bundle motility, which are interpreted as mechanical correlates of adaptation, depend on $\mathrm{Ca}^{2+}$.

\section{Mechanical consequences of channel gating}

Although electrical measurements show the open probability of a hair cell's transduction channels as a function of the hair-bundle deflection, mechanical measurements are even more revealing of how transduction occurs. An individual hair bundle can be studied in vitro by attaching to it the tip of a fine, horizontal, cylindrical glass fiber typically $100 \mu \mathrm{m}$ in length and $0.5 \mu \mathrm{m}$ in diameter $(87,88)$. Imaging the fiber's tip onto a photodiode pair then allows measurement of movements with a nanometer precision and a frequency response to about $1 \mathrm{kHz}$. Moreover, displacement of the fiber's base with a piezoelectric stimulator applies to the bundle a force that can be computed after calibration of the fiber. Through the use of feedback between bundle and fiber positions, an investigator can also impose more complex stimuli on a bundle $(15,89,90)$.

Because of thermal flickering of the transduction channels between their open and closed states, the tension in a gating spring is a stochastic variable. Its mean value 


$$
T_{\mathrm{GS}}=K_{\mathrm{GS}}\left(X+X_{\mathrm{R}}-D\right) P_{\mathrm{o}}+K_{\mathrm{GS}}\left(X+X_{\mathrm{R}}\right)\left(1-P_{\mathrm{o}}\right)=K_{\mathrm{GS}}\left(X+X_{\mathrm{R}}-D P_{o}\right)
$$

depends on the channels' open probability $P_{o}(X)$ given by Equation 1 , and thus varies nonlinearly with the hair-bundle deflection $X$. We recall that $K_{\mathrm{GS}}$ is the gating-spring stiffness, $X_{\mathrm{R}}$ the gating-spring extension at rest, and $D$ the gating swing. The force $F$ required to deflect the hair bundle by a distance $X$ is then described by the sum of two contributions

$$
F=K_{\mathrm{GS}}\left(X+X_{\mathrm{R}}-D P_{o}\right)+K_{\mathrm{SP}}\left(X-X_{\mathrm{SP}}\right),
$$

corresponding to the tension $T_{\mathrm{GS}}$ in the gating springs, a nonlinear function of $X$, and a linear elastic restoring force from the stereociliary pivots of stiffness $K_{\mathrm{SP}}$ and equilibrium position $X_{\mathrm{SP}}$. The mechanical relaxation associated with channel gating-the result of the gating swing $D$-is of profound importance, for it introduces a mechanical nonlinearity with multiple consequences.

The most striking consequence of channel gating is its contribution to the stiffness $K_{\mathrm{HB}}=F^{\prime}$ of a hair bundle. Here and in the following, a prime denotes differentiation with respect to an appropriate variable, in this case the bundle's deflection $X$. From Eqs. 1 and 5 ,

$$
K_{\mathrm{HB}}=K_{G S}\left(1-D P_{\mathrm{o}}^{\prime}\right)+K_{\mathrm{SP}}=K_{\infty}-\frac{N Z^{2}}{k_{B} T} P_{o}\left(1-P_{o}\right) .
$$

We see that channel gating effectively softens the hair bundle, a phenomenon called gating compliance (91). Gating compliance reduces the bundle's stiffness by a maximal amount $\Delta K=N Z^{2} /\left(4 k_{\mathrm{B}} T\right)$ from the asymptotic value $K_{\infty}=K_{G S}+K_{\mathrm{SP}}$ that is measured at large negative $\left(P_{o} \cong 0\right)$ or positive $\left(P_{o} \cong 1\right)$ deflections. If the gating force $Z$ is sufficiently great, the hair-bundle stiffness can actually become negative for values of the open probability near one half (92). Such behavior inevitably leads to mechanical instability, which natural selection has exploited to engineer the hair cell's active process.

Channel gating has another remarkable consequence: it engenders an increase in the effective friction of a hair bundle, called the gating friction $(75,93,94)$. Because of the finite activation kinetics of the transduction channels, thermal equilibration of the channel's open probability is not instantaneous but occurs on a timescale 
$\tau_{\mathrm{C}}=10 \mu \mathrm{s}-1 \mathrm{~ms}$. As a result, when the bundle moves in response to a time-varying stimulus, channel-gating forces arise with a delay and are therefore dissipative. Gating friction is associated with a friction coefficient $\lambda_{C} \cong \Delta K \cdot \tau_{C}$ that can be large enough to dominate the viscous drag on micrometer-sized hair bundles and thus to limit the kinetics of bundle movements. Perhaps to compensate for this effect, hair cells that respond to higher frequencies are endowed with faster transduction channels (95) that impose less gating friction.

Gating compliance and gating friction, which are intimately related to the mechanosensitivity of transduction channels, impose a reciprocal relation between stimulus forces and channel gating. External forces affect the open probability of the channels by changing the elastic energy stored in the gating springs; in return, channel gating changes the extension of the gating springs, producing internal forces-gating forces-that affect both the stiffness and the friction of the hair bundle. This framework can be generalized to any system comprising bistable elastic elements, as has been proposed for instance for muscle fibers (96-98).

\section{Resonant mechanical tuning from active hair-bundle motility}

The inner ears of vertebrates operate in a liquid environment in which hydrodynamic damping is inescapable. For a mechanically passive hair bundle of height $5 \mu \mathrm{m}$, the bundle's stiffness $k \approx 2 \mathrm{mN} \cdot \mathrm{m}^{-1}$, viscous-drag coefficient $\lambda \approx 100 \mathrm{nN} \cdot \mathrm{s} \cdot \mathrm{m}^{-1}$, and mass $m \approx 50 \cdot 10^{-15} \mathrm{~kg}$ yield a quality factor $Q=\sqrt{\mathrm{km}} / \lambda=0.1$. These values are typical for vestibular hair cells or low-frequency cochlear hair cells with characteristic frequencies in the kilohertz range. At the highest frequencies audible by any mammal, which are about a hundredfold as great, the corresponding bundles are a fifth as tall and are expected to be approximately one hundredfold as stiff $(30,31)$. Assuming that the bundle's mass and friction coefficient vary only weakly along the tonotopic axis of auditory organs (99), the

quality factor likely remains below unity: most passive hair bundles are overdamped (but 
see (100-102)). Inertial loading of the hair bundle with an accessory structure such as the tectorial membrane in the mammalian cochlea (103) can promote moderate mechanical resonance, but cannot account for the sharp tuning observed in vivo at the level of the basilar membrane and auditory nerve, with quality factors that can reach 1000 in some bats (104). These considerations pose a challenge: how might strong resonance occur under such highly damped conditions?

The hair bundle is mechanically active $(16,34,105)$. By mobilizing energy resources of biochemical origin, a hair cell can power active movements of its hair bundle to boost the bundle's performance as a mechanoelectrical transducer. Active hair-bundle motility displays several manifestations. A quiescent hair bundle can respond to a force step with a twitch (106) - a transient movement with a directionality opposite that of the applied force-or by developing a net pulling force on an attached fiber (107), a phenomenon analogous to the stretch activation of muscle. These properties are advantageous for sensitive detection of step stimuli, such as those evoked by abrupt head or fluid movements in vestibular or lateral-line organs, respectively. Hair bundles can also oscillate spontaneously $(58,87,108)$, a phenomenon that likely underlies spontaneous otoacoustic emission, the unprovoked emanation of sound from an ear (109).

Active motility provides a decisive functional advantage for hearing, for an oscillatory hair bundle amplifies periodic inputs near the natural frequency of spontaneous oscillations, thus enhancing the sensitivity and sharpening the frequency selectivity of auditory detection (108). The extra- and intracellular $\mathrm{Ca}^{2+}$ concentrations, the membrane potential at rest, the stiffness of an elastic load, and constant external forces have been identified as possible control parameters of hair-bundle activity. Varying one of these parameters elicits transitions between one form of motility and another $(57,89,110,111)$; individual bundles can thus operate in multiple mechanosensory modes. Of particular importance for the physics of hearing, transitions between quiescence and spontaneous oscillation position the hair bundle near a Hopf bifurcation $(112,113)$. At this operating point, the hair bundle shows signatures of the generic properties of any dynamical system 
operating near a Hopf bifurcation-a critical oscillator: amplification with a specific form of compressive nonlinearity and sharp frequency tuning, both of which depend on the magnitude of stimulation (Equation 20).

A common strategy in considering active hair-bundle motility is to present the experimentally observed phenomena, then to encapsulate them in a physical model. Here we proceed in the opposite direction, starting from a minimal abstract model and subsequently incorporating details about its biological implementation. We hope by the means to demonstrate the generic features of hair-cell activity and to emphasize that the experimental data might reflect any of several mechanisms, or indeed a combination of them.

The dissipation of power during spontaneous activity and the power gain during amplification (108), associated with violation of the fluctuation-dissipation theorem (114), indicate that the hair bundle is driven out of equilibrium by an Internal energy source that produces an active mechanical force $F_{A}$ on the bundle. Neglecting mass in view of the overdamped mechanics of a passive hair bundle, we write a linear equation of motion to describe the bundle's movements:

$$
\lambda \dot{X}=-k X+F_{A}+F,
$$

in which $X$ represents a small hair-bundle deflection with respect to a fixed point, $\lambda$ is the friction coefficient associated with the bundle's movement, and $k$ is the bundle's stiffness. $F$ denotes an externally applied force, especially that owing to auditory stimulation. Here and below, overdots represent temporal derivatives of the corresponding orders. To drive oscillations, the active force $F_{A}$ must provide feedback on the hair-bundle position $X$. We write to linear order

$$
\tau_{A} \dot{F}_{A}=\bar{k} X-F_{A},
$$

in which $\tau_{A}$ is the time constant of the force feedback and $\bar{k}$ represents the stiffness of the elastic element that mediates this feedback. We shall see below how these two parameters can be related to the timescale of adaptation and to gating-spring stiffness, respectively. 
The two equations may be combined into a single, second-order relation:

$$
m_{E F F} \ddot{X}=-\lambda_{E F F} \dot{X}-k_{E F F} X+\bar{F} .
$$

This representation maps the dynamical system to a classic harmonic resonator with effective mass $m_{E F F}=\lambda \tau_{A}$, drag coefficient $\lambda_{E F F}=\lambda+k \tau_{A}$, and stiffness $k_{E F F}=k-\bar{k}$. In the ensuing analysis, this formulation offers the didactic advantage of delineating how the components of specific implementations contribute to resonant frequency tuning. Note that the effective force

$$
\bar{F}=F+\tau_{A} \dot{F}
$$

applied to the system depends both on the actual force $F(t)$ applied to the hair bundle and on its time derivative. During sinusoidal stimulation $F(t)=\tilde{F} e^{-i \omega t}+\tilde{F}^{*} e^{+i \omega t}$, the effective force $\bar{F}(t)$ remains sinusoidal but with an altered phase and amplitude with respect to $F(t)$. Because Equation 9 is linear, the system responds at the frequency of the stimulus, with $X(t)=\tilde{X} e^{-i \omega t}+\tilde{X}^{*} e^{+i \omega t}$.

Although we have neglected the bundle's actual mass in our description of hairbundle mechanics (Equation 7), the interplay between hair-bundle mechanics and delayed force feedback endows the hair bundle with effective inertia. Force feedback also affects both the bundle's apparent friction coefficient and its stiffness. When the bundle's stiffness is positive $(k>0)$, force feedback increases friction. However, as described earlier, a defining property of mechanosensitive ion channels is gating compliance: channel gating produces a mechanical relaxation that effectively softens the gating springs (Equation 6), an effect that can be strong enough to result in negative stiffness of the hair bundle. When a hair bundle operates at a position of negative stiffness $(k<0)$, force feedback reduces friction on the hair bundle.

A key feature of the active system in the absence of an external force $(F=0)$ is that stability vanishes when $\lambda_{\mathrm{EFF}}=\lambda+k \tau_{\mathrm{A}}=0$, the condition for a Hopf bifurcation. Spontaneous oscillations then emerge at the natural frequency $\omega_{0}=\sqrt{k_{\mathrm{EFF}} / m_{\mathrm{EFF}}}$, which can be expressed as 


$$
\omega_{0}=\sqrt{(k-\bar{k}) /\left(\lambda \tau_{\mathrm{A}}\right)} .
$$

When operating on the stable side of the bifurcation $\left(\lambda_{\mathrm{EFF}}>0\right)$ and when stimulated at a frequency $\omega \cong \omega_{0}$, the system becomes highly resonant in response to an external sinusoidal force $F$ if the effective friction $\lambda_{\mathrm{EFF}}$ becomes small enough. The quality factor then obeys $Q=\sqrt{k_{\mathrm{EFF}} m_{\mathrm{EFF}}} / \lambda_{\mathrm{EFF}}=\sqrt{(k-\bar{k}) \lambda \tau_{\mathrm{A}}} /\left(\lambda+k \tau_{\mathrm{A}}\right) \gg 1$. Precisely at the Hopf bifurcation, Equation 9 indicates that the complex impedance $A(\omega)=\tilde{F}(\omega) / \tilde{X}(\omega)=$ $\mathrm{k}_{E F F}\left[1-\left(\omega / \omega_{0}\right)^{2}\right] /\left(1-i \omega \tau_{\mathrm{A}}\right)$ of the critical oscillator vanishes at the oscillator's natural frequency $\omega=\omega_{0}$. Both the quality factor and linear sensitivity $\chi=1 /|\tilde{A}|$ to the stimulus then formally diverge and the magnitude of the response falls under the control of nonlinearities that are discussed below (Equation 20).

As in any harmonic resonance, high sensitivity to sinusoidal stimulation at resonance is associated with sharp frequency selectivity, a property that is obviously advantageous for sound detection. The system is actively tuned at a natural frequency $\omega_{0}$ (Equation 11) that appears as the inverse geometric mean of two timescales: the characteristic time $\tau_{\mathrm{A}}$ of the active force feedback and the mechanical response time $\tau_{\mathrm{MEC}}=\lambda /(k-\bar{k})$ to small step forces. Frequency tuning is an emergent property of the interplay between passive hair-bundle mechanics and active force feedback. The natural frequency depends on parameters that control the bundle's stiffness and friction as well as on the timescale of the active feedback.

The imaginary part $A^{i}$ of the complex impedance $A(\omega)=\tilde{F}(\omega) / \tilde{X}(\omega)$ betrays the mechanical activity of the system. From Equation 9, we write

$$
A^{i}=k_{E F F} \omega \tau_{\mathrm{A}}\left[\left(1-\left(\frac{\omega}{\omega_{0}}\right)^{2}\right)-\frac{1}{\omega_{0} \tau_{\mathrm{A}} Q}\right] /\left[1+\left(\omega \tau_{\mathrm{A}}\right)^{2}\right] .
$$

As the system traverses a Hopf bifurcation $(Q \rightarrow+\infty), A^{i}$ changes sign at $\omega=\omega_{0}: A^{i}>0$ for stimulation at a frequency below the system's natural frequency $\left(\omega<\omega_{0}\right)$ and conversely $A^{i}<0$ for stimulation above the natural frequency $\left(\omega>\omega_{0}\right)$. This behavior is generic for Hopf oscillators (115). Positive values of $A^{i}$ correspond to active energy pumping into the surrounding fluid-negative dissipation. A passive harmonic oscillator 
must instead dissipate energy $\left(A^{i}<0\right)$ at all frequencies. As long as the timescale of the active force feedback is great enough that $\omega_{0} \tau_{\mathrm{A}} Q>1$, corresponding to $\tau_{\mathrm{A}}>\lambda /|\bar{k}|$, active energy pumping occurs even when the system (Eqs. 7-8) operates some distance from the Hopf bifurcation, though over the narrower range of frequencies $\omega<$ $\omega_{0} \sqrt{1-1 /\left(\omega_{0} \tau_{A} Q\right)}$. This situation is relevant to the cochlea, in which energy is pumped into the traveling wave basal to the position where the amplitude of vibration peaks (115, 116). The local response of the cochlea to weak sounds of varying frequency can actually be described by that of phenomenological oscillators obeying Equation 9, in which the stimulus $\bar{F}(t)$ corresponds—remarkably enough—to a combination of the pressure difference transverse to the basilar membrane and its weighted time derivative $(117,118)$. The phase advance of the force $\bar{F}$ driving the effective harmonic oscillator with respect to the phase of the actual external force $F$ again bespeaks the active nature of the force feedback provided by the adaptation process.

\section{Active force feedback from adaptation}

How is active force feedback (Equation 8) actually implemented by a hair cell? As discussed above, the hair bundle is endowed with a dynamic biasing mechanismadaptation-that continuously resets the bundle's open probability to the resting value $P_{o}^{\mathrm{R}}$ to prevent saturation and preserve sensitivity to weak, time-varying stimuli. Without loss of generality, we assume below that the operating point is at $P_{o}^{\mathrm{R}}=0.5$, corresponding to maximal displacement sensitivity. A minimal description of the interplay between overdamped, but nonlinear, hair-bundle mechanics and adaptation can be written as

$$
\begin{gathered}
\lambda \dot{X}=-K_{\mathrm{GS}}\left[X-D\left(P_{o}-0.5\right)\right]-K_{\mathrm{SP}} X+F, \\
\tau \dot{X}_{0}=X-X_{0},
\end{gathered}
$$

in which $P_{o}$ obeys Equation $1, K_{\mathrm{GS}}$ and $K_{\mathrm{SP}}$ are the respective contributions of the gating springs and stereociliary pivots to hair-bundle stiffness, and $\tau$ is the timescale of adaptation. In this instance, adaptation is described by a relaxation process of the set- 
point deflection $X_{0}$ toward the bundle's deflection $X$. In a steady state, $X=X_{0}=0$ and $P_{o}=0.5$. Through linear expansion about this fixed point, the nonlinear model described by Equations 13-14 can be mapped to the generic linear model for active hair-bundle motility (Eqs. 7-8) with $k=K_{\mathrm{GS}}\left(1-D P_{\mathrm{o}}^{\prime}\right)+K_{\mathrm{SP}}, \quad \bar{k}=-K_{\mathrm{GS}} D P_{o}^{\prime}, \quad F_{\mathrm{A}}=-K_{\mathrm{GS}} D P_{\mathrm{o}}^{\prime} X_{\mathrm{o}}=$ $-N Z P_{\mathrm{o}}^{\prime} X_{\mathrm{o}}$, and $\tau_{\mathrm{A}}=\tau$. We see that adaptation provides delayed force feedback on the hair bundle by responding to tension changes in the gating springs of stiffness $\bar{k}$, effectively producing the active force $F_{\mathrm{A}}$ given by the channel-gating force associated with a change in the set-point deflection $X_{0}$. The requirement of negative stiffness $(k<0)$ to bring the system near a Hopf bifurcation $(\lambda+k \tau \cong 0)$ imposes that gating compliance be sufficiently great.

Equation 14 captures the phenomenology of adaptation, but not its biological mechanism. As introduced earlier, two classes of models have been proposed to describe adaptation: those based on motor activity and on $\mathrm{Ca}^{2+}$-mediated channel reclosure. In the motor model, changes in the set-point deflection $X_{\mathrm{o}}$ result from movements $X_{\mathrm{A}}$ of myosin motors along the actin cores of the stereocilia, modulating tension in the tip links. Within this framework, we write $(57,58,75)$

$$
\begin{gathered}
\lambda \dot{X}=-K_{\mathrm{GS}}\left(X-X_{\mathrm{A}}-D P_{\mathrm{o}}\right)-K_{\mathrm{SP}} X+F, \\
\lambda_{\mathrm{A}} \dot{X}_{\mathrm{A}}=+K_{\mathrm{GS}}\left(X-X_{\mathrm{A}}-D P_{\mathrm{o}}\right)-F_{\mathrm{M}},
\end{gathered}
$$

with $P_{o}(X)=1 /\left\{1+\Lambda \exp \left[-\left(\mathrm{X}-\mathrm{X}_{\mathrm{A}}\right) / \delta\right]\right\}$ and $\Lambda=\exp \left[\Delta E^{\varnothing} /\left(\mathrm{k}_{B} T\right)\right]$ a constant that sets the channel's open probability when there is no tension in the tip links. The motor dynamics (Equation 16) is described by a linear relation of slope $\lambda_{\mathrm{A}}$ between the tension $T_{\mathrm{GS}}=K_{\mathrm{GS}}\left(X-X_{\mathrm{A}}-D P_{\mathrm{o}}\right)$ in the gating springs and the motor velocity $\dot{X}_{\mathrm{A}}$; the motors stall when gating-spring tension balances the force $F_{\mathrm{M}}$ produced by the motors. To account for $\mathrm{Ca}^{2+}$ effects on the operating point of the transducer (82) and on the kinetics of adaptation (78), we write that the motor force depends on the channels' open probability as

$$
F_{\mathrm{M}}=F_{\max }\left(1-S P_{\mathrm{o}}\right),
$$


in which $S$ represents the strength of $\mathrm{Ca}^{2+}$ feedback (75). In this formulation, the motor force is maximal when the channels are closed and the $\mathrm{Ca}^{2+}$ concentration at the motor site is low, but decreases when the channels open and allow an influx of $\mathrm{Ca}^{2+}$. Note that the strength of $\mathrm{Ca}^{2+}$ feedback is expected to increase with the extracellular $\mathrm{Ca}^{2+}$ concentration and at hyperpolarizing transmembrane potentials, both of which augment the $\mathrm{Ca}^{2+}$ influx through an open transduction channel and can be controlled experimentally $(57,119,120)$.

Again through linear expansion about a fixed point, the nonlinear motor-based model described by Eqs. 15-17 can be mapped to the generic linear model for active hairbundle motility (Eqs. 7-8). We then identify the stiffness $k=K_{G S}\left(1-D P_{\mathrm{o}}^{\prime}\right)+K_{\mathrm{SP}}$ of the hair bundle and the stiffness $\bar{k}=K_{\mathrm{GS}}\left(1-D P_{\mathrm{o}}^{\prime}\right)$ of the gating springs, both of which include gating compliance (Equation 6). The active force $F_{\mathrm{A}}=\bar{k} X_{\mathrm{A}}$ stems from a tension change in the gating springs of stiffness $\bar{k}$ as the result of the movement $X_{\mathrm{A}}$ of the motors; the time constant of the ensuing force feedback, or equivalently of adaptation, is

$$
\tau_{\mathrm{A}}=\lambda_{\mathrm{A}} /\left[K_{G S}\left(1-D P_{\mathrm{o}}^{\prime}\right)+S F_{\max } P_{\mathrm{o}}^{\prime}\right] .
$$

By controlling the value of $P_{0}^{\prime}$, the transducer's operating point affects the timescale of adaptation in remarkable ways (57). At an operating point near $P_{\mathrm{o}}=0.5$, where $P_{\mathrm{o}}^{\prime}$ peaks, strong $\mathrm{Ca}^{2+}$ feedback $\left(S F_{\max }>K_{\mathrm{GS}} D\right)$ reduces the time constant; adaptation can consequently be fast, occurring on timescales of a millisecond or less. Under conditions of weak $\mathrm{Ca}^{2+}$ feedback $\left(S F_{\max }<K_{\mathrm{GS}} D\right)$, gating compliance instead prevails and adaptation becomes quite slow $\left(\tau_{\mathrm{A}}>100 \mathrm{~ms}\right)$. At operating points where $P_{\mathrm{o}}^{\prime}$ is small, $P_{\mathrm{o}} \cong$ 0 or $P_{\mathrm{o}} \cong 1$, the timescale of adaptation is simply $\tau_{\mathrm{A}}=\lambda_{\mathrm{A}} / K_{\mathrm{GS}}$, which lies in the range of tens of milliseconds.

The requirement for negative stiffness $(k<0)$ to situate the hair bundle near a Hopf bifurcation implies that gating compliance is strong enough to impose $\bar{k}<0$. However, the $\mathrm{Ca}^{2+}$-feedback strength must then be great enough to keep $\tau_{\mathrm{A}}>0$, but not too large to maintain the system at a stable fixed point $(\lambda+k \tau \geq 0)$. The hair bundle cannot oscillate spontaneously in the absence of $\mathrm{Ca}^{2+}$ feedback $(S=0)$. We note that groups of molecular 
motors under elastic loading, embodied here by myosin motors pulling on tip links, can in principle oscillate collectively even with no $\mathrm{Ca}^{2+}$ feedback (121-123); this is not the case in the hair cell (58). At the Hopf bifurcation, spontaneous oscillations occur at a frequency that grows with the strength $S$ of $\mathrm{Ca}^{2+}$ feedback and the maximal force $F_{\max }$ that the motors can produce (Eqs. 11 and 18). In keeping with this reasoning, the conductance of the transduction channels and the tip-link tension increase with the natural frequency of hair cells along the tonotopic axis of the cochlea $(31,53,124)$.

In the alternative formulation, the $\mathrm{Ca}^{2+}$-reclosure model of adaptation postulates that $\mathrm{Ca}^{2+}$ affects the intrinsic energy difference $\Delta E^{\varnothing}$ of the transduction channel between its closed and open states by binding to the channel or an associated protein and stabilizing the closed state. As in the motor-based model, this mechanism changes the set-point deflection $X_{0}$ and shifts the relation $P_{\mathrm{o}}(X)$ in the direction of the hair-bundle deflection $X$. Motors remain necessary to provide tension in the tip links and to set an operating point at rest within the steep region of the sigmoidal relation $P_{0}(X)$. However, the motors in this instance do not move on the short timescales associated with auditory frequencies.

Under these assumptions, the equation of motion for the hair bundle is given by Equation 13. To describe adaptation (125), we assume that the set-point deflection $X_{0}(C)$ is a function of the $\mathrm{Ca}^{2+}$ concentration $C$ at the binding site; the channels' open probability still obeys Equation 1. We further assume that the kinetics of adaptation is limited by diffusion from the channel's pore to the $\mathrm{Ca}^{2+}$-binding site and thus by the timescale $\tau$ of $\mathrm{Ca}^{2+}$-concentration changes there. We write

$$
\tau \dot{C}=C_{0}+C_{1} P_{\mathrm{o}}-C,
$$

in which $C_{0}$ and $C_{0}+C_{1}$ are the steady-state $\mathrm{Ca}^{2+}$ concentrations when the channels are closed $\left(P_{\mathrm{o}}=0\right)$ and open $\left(P_{\mathrm{o}}=1\right)$, respectively. Linearization about a fixed point brings this nonlinear $\mathrm{Ca}^{2+}$-reclosure model (Equations 13 and 19) to the form of the generic linear model (Equations 7-8) of active hair-bundle motility with $k=K_{\mathrm{GS}}\left(1-D P_{\mathrm{o}}^{\prime}\right)+K_{\mathrm{SP}}$, $\bar{k}=-[\mu /(1+\mu)] K_{\mathrm{GS}} D P_{\mathrm{o}}^{\prime}, \quad F_{\mathrm{A}}=-\mu K_{\mathrm{GS}} D C / C_{1}$, and $\tau_{\mathrm{A}}=\tau /(1+\mu)$. The dimensionless parameter $\mu=C_{1} P_{0}^{\prime} X_{0}^{\prime}$ characterizes the $\mathrm{Ca}^{2+}$ sensitivity of the transducer. As with the 
motor model, a Hopf bifurcation can occur if the gating compliance is strong enough to mediate negative bundle stiffness $(k<0)$. In addition, the $\mathrm{Ca}^{2+}$ sensitivity $\mu$ must be large enough to impose $k_{\mathrm{EFF}}=k-\bar{k}>0$, but not too large to maintain the system at criticality $\left(\lambda+k \tau_{\mathrm{A}} \cong 0\right)$. Note that other formulations of the $\mathrm{Ca}^{2+}$-reclosure model have been proposed; for example, the kinetics of adaptation might be limited by the rate constant for $\mathrm{Ca}^{2+}$ binding (81). The uncertainty about this issue might be resolved by the identification of the $\mathrm{Ca}^{2+}$-binding molecule, perhaps the protein $\mathrm{CIB2}(126,127)$.

This analysis emphasizes the dynamic interplay between negative stiffness resulting from passive gating forces produced by the transduction channels and delayed force feedback provided by myosin motors and $\mathrm{Ca}^{2+}$ binding. By actively reducing the friction on a hair bundle and by effectively increasing the bundle's mass, this interplay can bring an overdamped hair bundle near a Hopf bifurcation, where the bundle becomes highly resonant in response to sinusoidal stimuli near the natural frequency of the oscillatory instability. This frequency is an emergent property that depends on the passive mechanical properties of the bundle as well as the parameters that condition the kinetics and magnitude of the active force feedback. Multiple parameters can be tuned to adjust the characteristic frequency at which the active bundle responds most sensitively to an incoming sound. It is thus no wonder that the number and height of stereocilia within a hair bundle (27-29), the stiffness and tension of the tip links (31), the conductance and activation kinetics of the transduction channels $(128,129)$, and the concentration of $\mathrm{Ca}^{2+}$ buffers in hair cells (130) display gradients along auditory organs.

\section{The auditory nonlinearity}

The most striking manifestations of the ear's complexity are the signs of nonlinearity. The ear does not operate as a high-fidelity sound receiver, but instead introduces distortions"phantom tones"- that modify the acoustic input (131). The sound that we perceive is consequently not precisely the sound to which we are exposed! The properties of the 
auditory nonlinearity have been extensively studied through psychophysical experiments (132). Some distortions are expected, of course, from the saturating nonlinearity imposed by the sigmoidal relation between the hair bundle's deflection and the open probability of the transduction channels (Equation 1) and from the ensuing mechanical nonlinearity in the force-displacement relation of the hair bundle (Equation 5) (133). However, this static nonlinearity alone does not explain the remarkable properties of auditory distortions. Instead, the properties of two-tone distortions in hearing are consistent with an "essential nonlinearity" for which there is no stimulus weak enough to elicit a linear response (132, 134). Thus the problem is not to understand saturation at high levels, which is expected, but rather why the ear remains nonlinear even at very low levels of stimulation. What is the basis of the ear's peculiar nonlinearity?

The generic nonlinearity associated with any active dynamical system operating near a Hopf bifurcation—a critical oscillator-provides a powerful and economic means to interpret the most salient properties of the cochlea and of two-tone distortions (115, 135). As discussed above in the context of active hair-bundle motility, the complex impedance $A(\omega)=\tilde{F}(\omega) / \tilde{X}(\omega)$ of a critical oscillator vanishes in response to sinusoidal stimulation at the oscillator's natural frequency. To leading order of a general series expansion (136), operation near a Hopf bifurcation mandates that the relation in the Fourier domain between the response $\widetilde{X}$ and the force $\widetilde{F}$ adopt the cubic form

$$
\tilde{F} \cong A \tilde{X}+B|\tilde{X}|^{2} \tilde{X}
$$

in which $B$ is a complex coefficient that describes the magnitude of the nonlinear term. At the Hopf bifurcation and for stimulation at the natural frequency $\omega_{0}$, the response $|\tilde{X}| \propto$ $|\tilde{F}|^{1 / 3}$ and the sensitivity $\chi \propto|\tilde{F}|^{-2 / 3}$ display characteristic power-law behaviors. At a given force amplitude, the relation between the frequency and sensitivity displays a peak centered at $\omega_{0}$ with a width $\Delta \omega \propto|\tilde{F}|^{2 / 3}$ that increases with the magnitude of the force and is inversely related to the sensitivity $(115,137,138)$.

A critical oscillator is thus endowed with automatic gain control and frequency selectivity: the weakest stimuli are detected with highest sensitivity and sharpest 
frequency selectivity, but the sensitivity and selectivity deteriorate as the magnitude of the stimulus rises. These remarkable properties recapitulate those observed experimentally both for a single hair bundle (139) and for the basilar membrane (140). As a result of nonlinear amplification, forces that elicit vibrations beyond a given threshold can be much weaker than in the passive case, greatly expanding the dynamic range. However, these benefits come at a cost: the nonlinearity associated with the Hopf bifurcation (Equation 20) distorts the response to a two-tone stimulus when the stimulus frequencies $f_{1}$ and $f_{2}$ fall within the active bandwidth $\Delta \omega$ of the nonlinear amplifier. The one-third power law $|\tilde{X}| \propto|\tilde{F}|^{1 / 3}$ between the local input and the response, which is intimately coupled with frequency selectivity, provides the essential nonlinearity needed to account for twotone interference in hearing $(134,135,141)$. Distortion products are observed in mechanical vibrations of the basilar membrane and can be strong enough to be detected in the ear canal as sounds called distortion-product otoacoustic emissions. For weak sound stimuli, the strongest of these emissions, which occurs at the same frequency $2 f_{1}-$ $f_{2}$ as the dominant phantom tone that is perceived, is actually used as a non-invasive hearing test for newborns.

Auditory detection by critical oscillators provides a physical principle to apprehend key features of the complex phenomenology evinced by the cochlea (115), and more generally by the active hearing of many vertebrates and some insects (142). Within this framework, sensitivity, frequency selectivity, and nonlinearity are intimately related and interdependent. In a minimal description of the mammalian cochlea, the organ is reduced to a set of critical oscillators with natural frequencies distributed along a tonotopic axis; fluid coupling between the oscillators results in active travelling waves that recapitulate the most salient features of experimental observations $(143,144)$. However, contrary to the experimental observation (140), in current models of the cochlea based on critical oscillators resonances are very sharp at low stimulus levels, as should be the case if the response is dominated by the local response of the oscillator driven at its natural frequency. This discrepancy might be resolved by taking into account viscoelastic 
longitudinal coupling between oscillators tuned to different frequencies $(14,145,146)$ and noise inherent to hair cells $(75,147)$. Coupling must result in a collective response that is nontrivially related to the local nonlinear properties of the individual oscillators.

\section{Physical limits to auditory sensitivity}

Near the hearing threshold, the ear responds to mechanical vibrations with amplitudes that are so low that they become comparable to-or even smaller than-thermal fluctuations of the ear's constituents. The Hopf bifurcation, however, is a mathematical property of deterministic dynamical systems; its generic properties can only approximate the behavior of biological systems. Noise blurs the Hopf bifurcation by destroying the phase coherence of weak oscillations and imposes non-vanishing values of the oscillator's complex impedance. An active resonance to weak stimuli can still occur, but with noise-limited values of the quality factor $(75,147)$. A critical oscillator with added noise effectively behaves as a noiseless oscillator operating on the stable side of a Hopf bifurcation, with parameters renormalized by the noise intensity and nonlinearities (148). As a result of noise, there is no true essential nonlinearity: the response always starts to grow linearly at some low stimulus level before displaying the one-third power law expected for a critical oscillator. This behavior is actually observed in experiments, both for single hair cells (139) and for the basilar membrane (149).

Mechanical coupling between identical noisy oscillators provides a means of achieving greater sensitivity to low stimulus levels and thus of increasing the signal-tonoise ratio: coupling results in synchronization that effectively reduces the noise intensity,

approaching more closely the behavior of a critical oscillator $(14,15)$. The larger the number of oscillators in a cluster, the more sensitive and frequency-selective the detection and the greater the quality factor of the resonance. This property is relevant to bats, some of which mobilize nearly half of the cochlea, corresponding to some 2,000 outer hair cells, for echolocation near a single frequency. The quality factor of the 
resonance accordingly reaches values exceeding 1,000 (104). Most mammals, including humans, distribute their hair cells more uniformly along the tonotopic map and thus devote a much smaller number of cells, probably about 100 , to the detection of any given frequency. Tuning is correspondingly much broader than in bats, with quality factors of 10-20 (150). In summary, owing to the limited number of hair cells available, there is a tradeoff between frequency selectivity at a particular frequency and the range of frequencies over which the organ can operate with high frequency selectivity.

\section{Conclusion}

Although we now have a good grasp of the activity of individual hair cells, we understand less well the subtle operation of the mammalian cochlea. Lodged in the hardest bone of the body, the cochlea is a small, delicate, metabolically vulnerable organ whose operation is readily compromised by experimental intervention. Because movements of the relevant structures are of nanometer dimensions, complex interferometric apparatus is required to make measurements. The organ is largely transparent, so the optical signals are weak and even the best apparatus cannot detect some movements. Moreover, it is difficult to sustain the active features of the cochlea under in vitro conditions. Most importantly, we have only a rudimentary understanding of the emergent properties associated with the activity of multiple cochlear hair cells that are coupled through a complex mechanical and hydrodynamic environment.

Progress in our understanding of the cochlea will likely emerge from the interplay of two approaches. The first is improvement in the techniques for measuring cochlear motions. Optical coherence tomography has recently revolutionized such recordings and should improve further as it is adapted for the special needs of auditory physiology. The second is theoretical modeling on the basis of physical principles. For more than 50 years, mathematical approaches have been of critical importance in understanding the propagation of cochlear traveling waves. More recently, bifurcation theory has illuminated 
the nonlinear behavior of active hair cells. As new data emerge, theoretical analysis must accommodate the characteristic features of cochlear hair cells: profound nonlinearity, stochasticity owing to a noisy environment, and the out-of-equilibrium operation associated with the ear's remarkable active process.

\section{Disclosure statement}

The authors are not aware of any affiliations, memberships, relationships, funding, or financial holdings that might affect the objectivity of this review.

\section{Acknowledgments}

The authors are grateful to the members of their research groups for comments on the manuscript. PM is supported by the French National Research Agency, from grants ANR16-CE13-0015, ANR-11-LABX-0038, and ANR-10-IDEX-0001-02. AJH is an Investigator of Howard Hughes Medical Institute.

\section{References}

ADDIN ZOTERO_BIBL \{"uncited":[],"omitted":[],"custom":[]\} CSL_BIBLIOGRAPHY 1.

Manley GA. 2000. Proc. Natl. Acad. Sci. U. S. A. 97(22):11736-43

2. Fettiplace R. 2020. Trends Neurosci. 43(2):88-102

3. von Békésy G. 1960. Experiments in Hearing. New York: McGraw-Hill

4. Aranyosi AJ, Freeman DM. 2004. Biophys. J. 87(5):3536-46

5. Freeman DM, Weiss TF. 1990. Hear. Res. 48(1-2):37-67

6. Fettiplace R, Crawford AC. 1980. Hear. Res. 2(3-4):447-54

7. Crawford AC, Fettiplace R. 1980. J. Physiol. 306:79-125

8. Crawford AC, Fettiplace R. 1981. J. Physiol. 312:377-412 
9. Hudspeth AJ, Lewis RS. 1988. J. Physiol. 400:237-74

10. Hudspeth AJ, Lewis RS. 1988. J. Physiol. 400:275-97

11. Bruns V, Schmieszek E. 1980. Hear. Res. 3(1):27-43

12. Kössl M, Vater M. 1985. J. Comp. Physiol. [A]. 157(5):687-97

13. Vater M, Kössl M. 2011. Hear. Res. 273(1-2):89-99

14. Dierkes K, Lindner B, Julicher F. 2008. Proc. Natl. Acad. Sci. U. S. A. 105(48):18669-74

15. Barral J, Dierkes K, Lindner B, Jülicher F, Martin P. 2010. Proc. Natl. Acad. Sci. U. S. A. 107(18):8079-84

16. Hudspeth AJ. 2014. Nat. Rev. Neurosci. 15(9):600-614

17. Reichenbach T, Hudspeth AJ. 2014. Rep. Prog. Phys. Phys. Soc. G. B. 77(7):076601

18. Aibara R, Welsh JT, Puria S, Goode RL. 2001. Hear. Res. 152(1-2):100-109

19. Emadi G, Richter C-P, Dallos P. 2004. J. Neurophysiol. 91(1):474-88

20. Ruggero MA, Rich NC, Recio A, Narayan SS, Robles L. 1997. J. Acoust. Soc. Am. 101(4):2151-63

21. Robles L, Ruggero MA, Rich NC. 1986. J. Acoust. Soc. Am. 80(5):1364-74

22. Ren T, Nuttall AL. 2001. Hear. Res. 151(1-2):48-60

23. Fisher JAN, Nin F, Reichenbach T, Uthaiah RC, Hudspeth AJ. 2012. Neuron. 76(5):989_ 97

24. Cooper NP, Vavakou A, van der Heijden M. 2018. Nat. Commun. 9(1):3054

25. Retzius, G. Das Gehörorgan der Wirbelthiere. II. Das Gehörorgan der Reptilien, der Vögel und der Säugethiere

26. Jacobs RA, Hudspeth AJ. 1990. Cold Spring Harb. Symp. Quant. Biol. 55:547-61

27. Tilney LG, Tilney MS, DeRosier DJ. 1992. Annu. Rev. Cell Biol. 8:257-74

28. Wright A. 1984. Hear. Res. 13(1):89-98

29. Roth B, Bruns V. 1992. Anat. Embryol. (Berl.). 185(6):571-81 
30. Flock A, Strelioff D. 1984. Nature. 310(5978):597-99

31. Tobin M, Chaiyasitdhi A, Michel V, Michalski N, Martin P. 2019. eLife. 8:e43473

32. Hudspeth AJ, Corey DP. 1977. Proc. Natl. Acad. Sci. U. S. A. 74(6):2407-11

33. Shotwell SL, Jacobs R, Hudspeth AJ. 1981. Ann. N. Y. Acad. Sci. 374:1-10

34. Hudspeth AJ. 2008. Neuron. 59(4):530-45

35. Pickles JO, Comis SD, Osborne MP. 1984. Hear. Res. 15(2):103-12

36. Lumpkin EA, Hudspeth AJ. 1995. Proc. Natl. Acad. Sci. U. S. A. 92(22):10297-301

37. Beurg M, Fettiplace R, Nam J-H, Ricci AJ. 2009. Nat. Neurosci. 12(5):553-58

38. Keen EC, Hudspeth AJ. 2006. Proc. Natl. Acad. Sci. U. S. A. 103(14):5537-42

39. Li G-L, Keen E, Andor-Ardó D, Hudspeth AJ, von Gersdorff H. 2009. J. Neurosci. 29(23):7558-68

40. Moser T, Beutner D. 2000. Proc. Natl. Acad. Sci. U. S. A. 97(2):883-88

41. Marquis RE, Hudspeth AJ. 1997. Proc. Natl. Acad. Sci. U. S. A. 94(22):11923-28

42. Kazmierczak P, Sakaguchi H, Tokita J, Wilson-Kubalek EM, Milligan RA, et al. 2007. Nature. 449(7158):87-91

43. Bartsch TF, Hengel FE, Oswald A, Dionne G, Chipendo IV, et al. 2019. Proc. Natl. Acad. Sci. U. S. A. 116(22):11048-56

44. Gillespie PG, Wagner MC, Hudspeth AJ. 1993. Neuron. 11(4):581-94

45. Garcia JA, Yee AG, Gillespie PG, Corey DP. 1998. J Neurosci. 18(21):8637-47.

46. Holt JR, Gillespie SKH, Provance DW, Shah K, Shokat KM, et al. 2002. Cell. 108(3):371-81

47. Stauffer EA, Scarborough JD, Hirono M, Miller ED, Shah K, et al. 2005. Neuron. 47(4):541-53

48. Grati M, Kachar B. 2011. Proc. Natl. Acad. Sci. U. S. A. 108(28):11476-81 
49. Kros CJ, Marcotti W, van Netten SM, Self TJ, Libby RT, et al. 2002. Nat Neurosci. $5(1): 41-47$

50. Jia Y, Zhao Y, Kusakizako T, Wang Y, Pan C, et al. 2020. Neuron. 105(2):310-321.e3

51. Pan B, Geleoc GS, Asai Y, Horwitz GC, Kurima K, et al. 2013. Neuron. 79(3):504-15

52. Pan B, Akyuz N, Liu X-P, Asai Y, Nist-Lund C, et al. 2018. Neuron. 99(4):736-753.e6

53. Ricci AJ, Crawford AC, Fettiplace R. 2003. Neuron. 40(5):983-90

54. Beurg M, Xiong W, Zhao B, Müller U, Fettiplace R. 2015. Proc. Natl. Acad. Sci. U. S. A. 112(5):1589-94

55. Beurg M, Cui R, Goldring AC, Ebrahim S, Fettiplace R, Kachar B. 2018. Nat. Commun. $9(1): 2185$

56. Ramamoorthy S, Deo NV, Grosh K. 2007. J. Acoust. Soc. Am. 121(5):2758

57. Tinevez JY, Julicher F, Martin P. 2007. Biophys. J. 93(11):4053-67

58. Martin P, Bozovic D, Choe Y, Hudspeth AJ. 2003. J. Neurosci. 23(11):4533-48

59. Kennedy HJ, Evans MG, Crawford AC, Fettiplace R. 2003. Nat Neurosci. 6(8):832-36

60. $\quad$ Corey DP, Hudspeth AJ. 1983. J. Neurosci. 3(5):962-976.

61. Markin VS, Hudspeth AJ. 1995. Annu. Rev. Biophys. Biomol. Struct. 24:59-83

62. Assad JA, Shepherd GM, Corey DP. 1991. Neuron. 7(6):985-94

63. Hudspeth AJ. 1992. Soc. Gen. Physiol. Ser. 47:357-70

64. Hudspeth AJ, Gillespie PG. 1994. Neuron. 12(1):1-9.

65. Hirokawa N, Tilney LG. 1982. J. Cell Biol. 95(1):249-61

66. Tilney LG, Derosier DJ, Mulroy MJ. 1980. J. Cell Biol. 86(1):244-59

67. Russell I, Kössl M. 1992. Philos. Trans. R. Soc. Lond. B. Biol. Sci. 336(1278):317-24

68. Chiappe ME, Kozlov AS, Hudspeth AJ. 2007. J Neurosci. 27(44):11978-85

69. Russell I, Sellick P. 1983. J. Physiol. 338(1):179-206

70. Corns LF, Johnson SL, Kros CJ, Marcotti W. 2014. Proc. Natl. Acad. Sci. U. S. A. 
71. Kirk DL, Moleirinho A, Patuzzi RB. 1997. Hear. Res. 112(1-2):69-86

72. Patuzzi R, Rajan R. 1990. Hear. Res. 45(1-2):15-32

73. Bobbin RP, Salt AN. 2005. Hear. Res. 205(1-2):35-43

74. Ashmore JF. 1987. J. Physiol. 388:323-47

75. Nadrowski B, Martin P, Jülicher F. 2004. Proc. Natl. Acad. Sci. U. S. A. 101(33):12195200

76. $\quad$ Eatock RA, Corey DP, Hudspeth AJ. 1987. J. Neurosci. 7(9):2821-2836.

77. Howard J, Hudspeth AJ. 1987. Proc. Natl. Acad. Sci. U. S. A. 84(9):3064-3068.

78. Assad JA, Corey DP. 1992. J. Neurosci. 12(9):3291-3309

79. Hudspeth AJ, Gillespie PG. 1994. Neuron. 12(1):1-9.

80. Hacohen N, Assad JA, Smith WJ, Corey DP. 1989. J. Neurosci. 9(11):3988-97

81. Choe Y, Magnasco MO, Hudspeth AJ. 1998. Proc. Natl. Acad. Sci. U. S. A. 95(26):15321-26

82. Cheung ELM, Corey DP. 2006. Biophys. J. 90(1):124-39

83. Peng AW, Effertz T, Ricci AJ. 2013. Neuron. 80(4):960-72

84. Corns LF, Johnson SL, Kros CJ, Marcotti W. 2014. Proc. Natl. Acad. Sci. U. S. A. 111(41):14918-23

85. Peng AW, Gnanasambandam R, Sachs F, Ricci AJ. 2016. J. Neurosci. 36(10):2945-56

86. Effertz T, Becker L, Peng AW, Ricci AJ. 2017. J. Neurosci. 37(48):11632-46

87. Crawford AC, Fettiplace R. 1985. J. Physiol. 364:359-79

88. Howard J, Ashmore JF. 1986. Hear. Res. 23(1):93-104

89. Salvi JD, Ó Maoiléidigh D, Fabella BA, Tobin M, Hudspeth AJ. 2015. Proc. Natl. Acad. Sci. U. S. A. 112(9):E1000-1009

90. Jaramillo F, Hudspeth AJ. 1993. Proc. Natl. Acad. Sci. U. S. A. 90(4):1330-34

91. Howard J, Hudspeth AJ. 1988. Neuron. 1(3):189-99 
92. Martin P, Mehta AD, Hudspeth AJ. 2000. Proc. Natl. Acad. Sci. U. S. A. 97(22):12026-31

93. Bormuth V, Barral J, Joanny J-F, Jülicher F, Martin P. 2014. Proc. Natl. Acad. Sci. U. S.
A. 111(20):7185-90

94. Barral J, Jülicher F, Martin P. 2018. Biophys. J. 114(2):425-36

95. Ricci AJ, Kennedy HJ, Crawford AC, Fettiplace R. 2005. J. Neurosci. 25(34):7831-39

96. Huxley AF, Simmons RM. 1971. Nature. 233(5321):533-38

97. Caruel M, Allain JM, Truskinovsky L. 2013. Phys. Rev. Lett. 110(24):248103

98. Vilfan A, Duke T. 2003. Biophys. J. 85(2):818-27

99. Tilney LG, Tilney MS. 1988. J. Cell Biol. 107(6 Pt 2):2563-74

100. Frishkopf LS, DeRosier DJ. 1983. Hear. Res. 12(3):393-404

101. Holton T, Hudspeth AJ. 1983. Science. 222(4623):508-10

102. Aranyosi AJ, Freeman DM. 2004. Biophys. J. 87(5):3536-46

103. Gummer AW, Hemmert W, Zenner HP. 1996. Proc. Natl. Acad. Sci. U. S. A. 93(16):8727-32

104. Kossl M, Russell IJ. 1995. Proc. Natl. Acad. Sci. U. S. A. 92(1):276-79

105. Hudspeth AJ, Jülicher F, Martin P. 2010. J. Neurophysiol. 104(3):1219-29

106. Benser ME, Marquis RE, Hudspeth AJ. 1996. J. Neurosci. 16(18):5629-43

107. Kennedy HJ, Crawford AC, Fettiplace R. 2005. Nature. 433(7028):880-83

108. Martin P, Hudspeth AJ. 1999. Proc. Natl. Acad. Sci. U. S. A. 96(25):14306-11

109. Probst R. 1990. Adv. Otolaryngol. 44:1-97

110. Salvi JD, Ó Maoiléidigh D, Hudspeth AJ. 2016. Biophys. J. 111(4):798-812

111. Strimbu CE, Fredrickson-Hemsing L, Bozovic D. 2012. PloS One. 7(3):e33862

112. Camalet S, Duke T, Jülicher F, Prost J. 2000. Proc. Natl. Acad. Sci. U. S. A. 97(7):318388 
113. Milewski AR, Ó Maoiléidigh D, Salvi JD, Hudspeth AJ. 2017. Proc. Natl. Acad. Sci. U. S. A. 114(33):E6794-6803

114. Martin P, Hudspeth AJ, Jülicher F. 2001. Proc. Natl. Acad. Sci. U. S. A. 98(25):14380-85

115. Hudspeth AJ, Jülicher F, Martin P. 2010. J. Neurophysiol. 104(3):1219-29

116. Shera CA. 2007. J Acoust Soc Am. 122(5):2738-58

117. Zweig G. 2015. J. Acoust. Soc. Am. 138(2):1102-21

118. Altoè A, Shera CA. 2020. Phys. Rev. Res. 2(1):013218

119. Assad JA, Hacohen N, Corey DP. 1989. Proc. Natl. Acad. Sci. U. S. A. 86(8):2918-22

120. Crawford AC, Evans MG, Fettiplace R. 1991. J. Physiol. 434:369-98

121. Guerin T, Prost J, Martin P, Joanny JF. 2010. Curr Opin Cell Biol. 22(1):14-20

122. Jülicher F, Prost J. 1997. Phys. Rev. Lett. 78(23):4510-13

123. Placais PY, Balland M, Guerin T, Joanny JF, Martin P. 2009. Phys. Rev. Lett. 103(15):158102

124. Beurg M, Xiong W, Zhao B, Müller U, Fettiplace R. 2015. Proc. Natl. Acad. Sci. U. S. A. 112(5):1589-94

125. Vilfan A, Duke T. 2003. Biophys J. 85(1):191-203

126. Riazuddin S, Belyantseva IA, Giese APJ, Lee K, Indzhykulian AA, et al. 2012. Nat. Genet. 44(11):1265-71

127. Giese APJ, Tang Y-Q, Sinha GP, Bowl MR, Goldring AC, et al. 2017. Nat. Commun. $8(1): 43$

128. Ricci AJ, Crawford AC, Fettiplace R. 2003. Neuron. 40(5):983-90

129. Beurg M, Cui R, Goldring AC, Ebrahim S, Fettiplace R, Kachar B. 2018. Nat. Commun. 9(1):2185

130. Hackney CM, Mahendrasingam S, Penn A, Fettiplace R. 2005. J. Neurosci. 25(34):786775 
131. Avan P, Buki B, Petit C. 2013. Physiol. Rev. 93(4):1563-1619

132. Goldstein JL. 1967. J. Acoust. Soc. Am. 41(3):676-89

133. Jaramillo F, Markin VS, Hudspeth AJ. 1993. Nature. 364(6437):527-29

134. Smoorenburg GF. 1972. J Acoust Soc Am. 52:615-32

135. Jülicher F, Andor D, Duke T. 2001. Proc. Natl. Acad. Sci. U. S. A. 98(16):9080-85

136. Camalet S, Duke T, Jülicher F, Prost J. 2000. Proc. Natl. Acad. Sci. U. S. A. 97(7):318388

137. Stoop R, Kern A. 2004. Proc. Natl. Acad. Sci. U. S. A. 101(25):9179-81

138. Eguiluz VM, Ospeck M, Choe Y, Hudspeth AJ, Magnasco MO. 2000. Phys Rev Lett. 84(22):5232-5235.

139. Martin P, Hudspeth AJ. 2001. Proc. Natl. Acad. Sci. U. S. A. 98(25):14386-91

140. Robbles L, Ruggero MA. 2001. Physiol. Rev. 81(3):1305-52

141. Barral J, Martin P. 2012. Proc. Natl. Acad. Sci. U. S. A. 109(21):E1344-1351

142. Mhatre N. 2015. J. Comp. Physiol. A Neuroethol. Sens. Neural. Behav. Physiol. 201(1):19-37

143. Duke T, Julicher F. 2003. Phys. Rev. Lett. 90(15):158101

144. Magnasco MO. 2003. Phys. Rev. Lett. 90(5):058101

145. Fruth F, Julicher F, Lindner B. 2014. Biophys J. 107(4):815-24

146. Meaud J, Grosh K. 2010. J. Acoust. Soc. Am. 127(3):1411-21

147. Julicher F, Dierkes K, Lindner B, Prost J, Martin P. 2009. Eur Phys J E Soft Matter. 29(4):449-60

148. Dinis L, Martin P, Barral J, Prost J, Joanny JF. 2012. Phys. Rev. Lett. 109(16):160602

149. Ruggero MA, Rich NC, Recio A, Narayan SS, Robles L. 1997. J. Acoust. Soc. Am. 101(4):2151-63

150. Shera CA, Guinan JJ Jr, Oxenham AJ. 2002. Proc. Natl. Acad. Sci. U. S. A. 99(5):3318-23 


\section{Figures:}
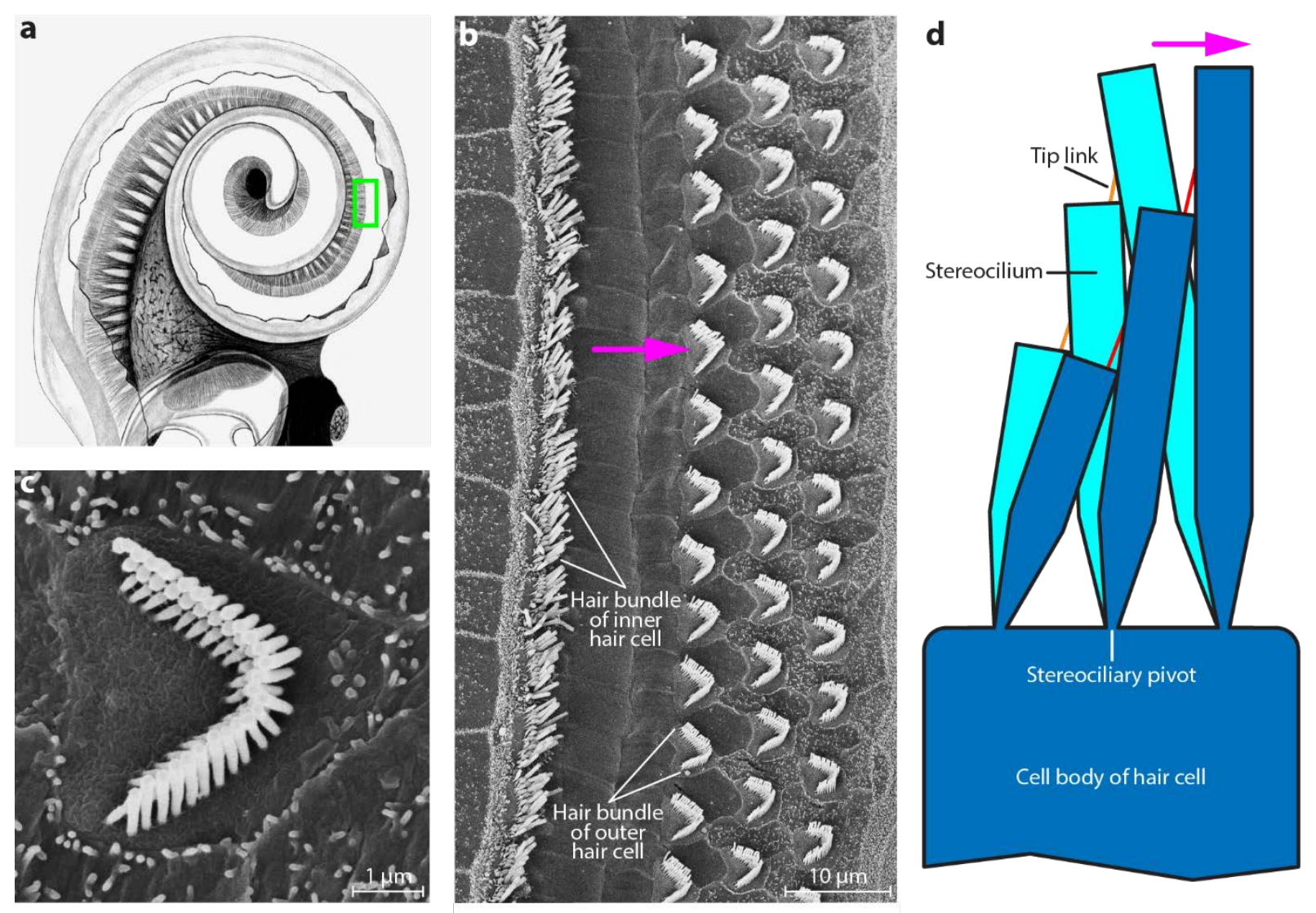

Figure 1

Mechanoelectrical-transduction apparatus of the mammalian cochlea. (a) A drawing of the human cochlea (modified from reference 25 ) shows nearly three tapered helical turns. The green rectangle at the right represents an area corresponding to that in panel $(b)$. (b) A scanning electron micrograph of a mouse's cochlea portrays the surface of the sensory epithelium, including the top surfaces and hair bundles of inner and outer hair cells. Deflecting the top of any hair bundle to the right (arrow), away from the central axis of the cochlear helix, excites the associated hair cell. (c) The heart-shaped top surface of an outer hair cell bears approximately 70 upright stereocilia in three rows that increase in 
height from the left to the right edge. (d) A schematic diagram shows the operation of a simplified hair bundle. At rest (light blue), the tip link (orange) atop each stereocilium bears relatively little tension and many of the transduction channels are closed. When mechanical force (arrow) in the excitatory direction deflects the bundle (dark blue), the stereocilia pivot at their basal insertions onto the hair cell's body. Shear between the contiguous stereocilia then stretches the tip links (red), whose increased tension opens more channels. The sizes of the tip links have been exaggerated severalfold, and the bundle's motion ten- to a thousand-fold, in comparison to the hair bundle's dimensions. 


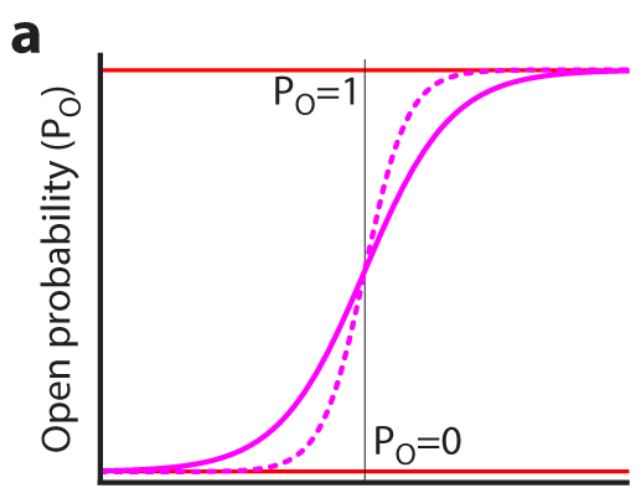

b
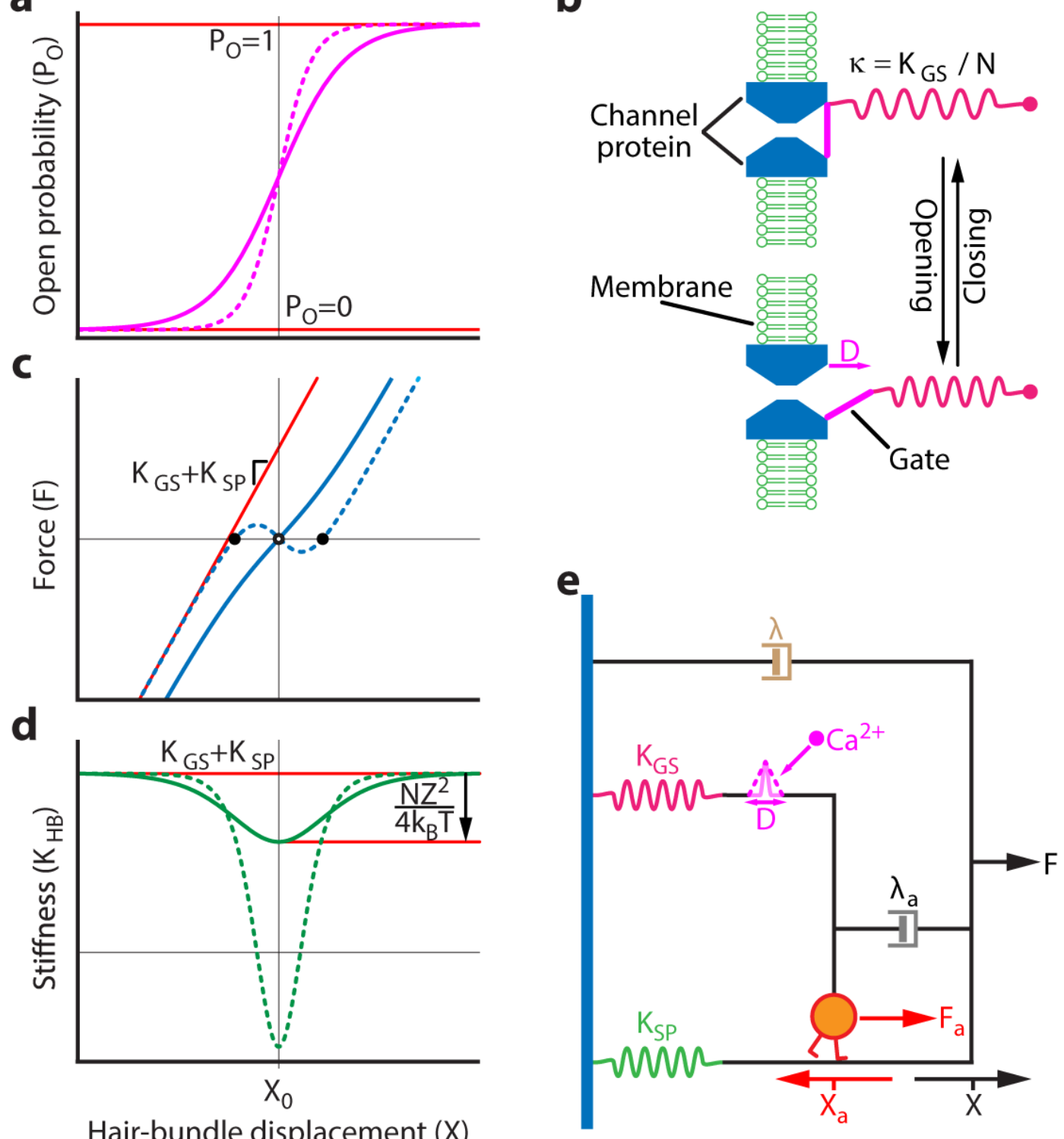

Figure 2

The physical basis of active hair-bundle mechanosensitivity. (a) The open probability $P_{o}$ of transduction channels displays a sigmoidal Boltzmann relation to hair-bundle displacement $\mathrm{X}$. The displacement at which half the channels are open is denoted as $\mathrm{X}_{0}$. The curve is relatively shallow for a low gating force $\mathrm{Z}$ (continuous line), but steepens as the magnitude of the gating force increases (dashed line). The same line-style convention is used in panels $(c)$ and $(d)$. (b) In a simple description of mechanoelectrical transduction, 
each channel has two states-open and closed-and its molecular gate stochastically flickers between them under the influence of the tension in an associated gating spring of stiffness $\kappa$. Opening of a channel reduces the extension of and the tension in the gating spring by the gating swing $D$ and the gating force $Z=\kappa D$, respectively. Each hair bundle is endowed with $\mathrm{N}$ parallel transduction elements that together contribute a stiffness $\mathrm{K}_{\mathrm{GS}}=\mathrm{N \kappa}$. (c) The external force $\mathrm{F}$ required to deflect a hair bundle by an amount $\mathrm{X}$ deviates from linear, Hookean behavior over the narrow range of positions in which the channels' open probability changes significantly. For large negative or positive stimuli, the curve's slope $\mathrm{K}_{\infty}=\mathrm{K}_{\mathrm{GS}}+\mathrm{K}_{\mathrm{SP}}$ is the sum of the stiffness contributions $\mathrm{K}_{\mathrm{GS}}$ from the grating springs and $\mathrm{K}_{\mathrm{SP}}$ from the stereociliary pivots. The slope declines for intermediate values and can even become negative if the gating force is sufficiently great. Under force-clamp conditions (thin horizontal line), this behavior destabilizes the bundle's position $X=X_{0}$ at which $\mathrm{P}_{\mathrm{o}}=0.5$ (open circle) and the bundle becomes bistable, residing at either of two stable fixed points (solid circles). (d) The hair bundle's stiffness as a function of displacement is given by the slope of the preceding curve. The reduction of stiffness associated with channel opening and closing — the gating compliance-can reduce the stiffness until it becomes negative (dashed line). (e) An effective mechanical description of the hair bundle depicts a channel (pink) that opens or closes through distance D under the influence of tension in a gating spring of stiffness $\mathrm{K}_{\mathrm{GS}}$ (maroon). An external force $\mathrm{F}$ displaces the bundle a distance $\mathrm{X}$ by acting on the gating-spring stiffness $\mathrm{K}_{\mathrm{GS}}$ as well as on the stereociliary-pivot stiffness $\mathrm{K}_{\mathrm{SP}}$ (green) and the bundle's viscous drag of coefficient $\lambda$ (brown). Active force feedback on the bundle's displacement may proceed through two adaptation mechanisms that are not mutually exclusive. In the motor model, myosin molecules (red) move a distance $\mathrm{X}_{\mathrm{a}}$ to restore force balance between the motors' stall force $\mathrm{F}_{\mathrm{a}}$ and tension in the gating spring; the velocity of motion $\dot{\mathrm{X}}_{\mathrm{a}}$ is inversely related to the friction coefficient $\lambda_{a}$ (gray). In the $\mathrm{Ca}^{2+}$-reclosure model, $\mathrm{Ca}^{2+}$ that enters the stereocilium through transduction channels acts to reclose them. 